\title{
Deforestation Detection in Kinabalu Area, Sabah, Malaysia by using Multi-sensor Remote Sensing Approach
}

\author{
Mui-How Phua*1 and Satoshi Tsuyuki*2
}

\begin{abstract}
This paper examines use of multi-sensor remote sensing approach for deforestation detection in the tropics. Multi-sensor satellite data of Landsat-MSS of 1973 and Landsat -TM of 1991 and 1996 were employed. Accuracy of image-to-image registration was below 1 pixel. Relative radiometric normalization of Landat-MSS 1973 and LandsatTM 1991 to Landsat-TM 1996 as the reference image was carried out to remove the unwanted variabilities between all the satellite images. Image differencing algorithm with Normalized Difference Vegetation Index (NDVI) was examined for deforestation detection. The performance of the NDVI image differencing algorithm for deforestation detection between 1973 and 1996 was investigated at three test sites covered with reliable ground truths. The accuracy of detection was satisfactory that the algorithm was used in deforestation detection of the whole study area in two change periods i.e. I: 1973-1991 and II: 1991-1996. Although false deforestation pixels in period I were also detected, it can easily be rectified using a land use map of 1984. In total, 2,445ha of forest, which is almost $1 \%$ of the study area, were cleared from 1973-1996 and most of them were deforested in period I (2,090ha). This study concludes that the multi-sensor approach is a useful solution for deforestation detection because of better temporal coverage. It can also provide more satellite data for the application and thus lessen data acquisition problem due to cloud cover which is a consistent problem for the tropics.
\end{abstract}

Keywords: Deforestation detection, Multi-sensor remote sensing, Kinabalu Area

\section{INTRODUCTION}

Anthropogenic Activities and Deforestation

Deforestation has been one of the most important issues in the world especially in the tropics over the twentieth century. In this study, deforestation is defined as removal of forest cover to a state where the land surface becomes bare land. For mountainous areas, detecting and monitoring deforestation is even more important because of environmental impacts especially those related to landslide and soil loss. It is reported that agriculture is the main activity in the

\footnotetext{
${ }^{*}$ School of International Tropical Forestry, Universiti Malaysia Sabah, Locked bag 2073, 88999 Kota Kinabalu, Sabah, Malaysia e-mail: pmh@ums.edu.my

${ }^{* 2}$ Graduate School of Agricultural and Life Sciences, The University of Tokyo, 1-1-1 Yayoi, Bunkyo-ku, Tokyo, Japan 113-8657 e-mail: tsuyuki@fr.a.u-tokyo.ac.jp
}

Andean countries that cause deforestation and habitat destruction. The habitat destruction in the neotropic region has been concentrating at lower slope and elevation areas, especially below $1500 \mathrm{~m}$. Montane bird species have relatively narrow elevation ranges (STOTZ, 1998). Besides, many of the elevation migrants are intolerant of non-forest habitats (Powell and BJORK, 1995). Disruption of the movement pattern may provoke ecosystem-wide consequences due to the loss of their pollination and dispersal services (STOTZ, 1998). In Kinabalu area, land use activities have resulted forest clearings of steep slope areas. At the southern boundary area, ultrabasic forest which supports numerous endemic species, is found (KiTAYAMA, 1991a).

At a landscape scale, the anthropogenic activities can lead to habitat destruction that may cause some species become more vulnerable to extinction. Forest clearing as well as management activities for commercial timber production can fragment populations of forest dependent wildlife (LAMBERSON et al., 1994). The relationships between the species number and some landscape indices have been investigated (e.g. COLLINGE, 1996; DRESCHSLER and WISSEL, 1998).

Changes such as deforestation can easily be observed at 
the field but it is not easy to quantify the changes in terms of area, rate and distribution in the field. In fact, characteristics of deforestation may differ from place to place and thus need to be periodically examined and monitored.

\section{Remote Sensing for Deforestation Detection}

Change detection is the process of identifying differences in the state of an object or phenomenon by observing it at different times. Deforestation is a type of change can be detected using satellite remote sensing. The basic premise in using remote sensing data for deforestation detection is that changes in the forest cover will result in changes in radiance values that are separable from changes caused by other factors, such as differences in atmospheric conditions, illumination and viewing angle, soil moisture etc. It may further be necessary to require that changes of interest be separable from expected or uninteresting events, such as seasonal, weather, tidal or diurnal effects.

There have been many change detection studies in place (e.g. Singh, 1989; Cohen and FIorella, 1999; DhaKal, 1999; ANDRÉFOUËT et al., 2001). The common thing they share is that these studies usually employ single sensor data. This enables various techniques to be employed and tested for effectiveness in detecting temporal changes. However, change detection with single sensor data is restricted to the temporal coverage of the sensor. In contrast, the multi-sensor remote sensing approach has the absolute advantage for detecting changes in longer period and has more satellite images to choose from. The use of Lansat-MSS, in addition to the Landsat-TM, for instance, enables changes occurred back to 1972 when the Landsat-1 mission launched, to be investigated. Despite the absolute advantages, the use of this approach is relatively rare. MuNYATI (2000) exploited the temporal advantage for detecting wetland change using the Landsat-MSS and Landsat-TM data. Instead of using the widely recognized techniques such as image differencing, only classification was conducted but satisfying results were reported.

The objective of this study is to detect deforestation in Kinabalu area, Sabah, Malaysia by using multi-sensor remote sensing approach. It is also intended to examine the deforestation detection accuracy of the Normalized Difference Vegetation Index (NDVI) image differencing technique using the multi-sensor data. The multi-sensor data offer temporal coverage from 1970 s to 1990 s for detecting deforestation at Kinabalu area. The areas and distribution of deforestation at the study area are derived and causes are discussed.

\section{STUDY AREA}

Kinabalu area is located at the northeastern part of Kota Kinabalu, the capital of the state of Sabah, Malaysia (Fig. 1). Average, minimum and maximum rainfall of the study area are $3,274 \mathrm{~mm}, 2,451 \mathrm{~mm}$ and $5,487 \mathrm{~mm}$, respectively. The Kinabalu

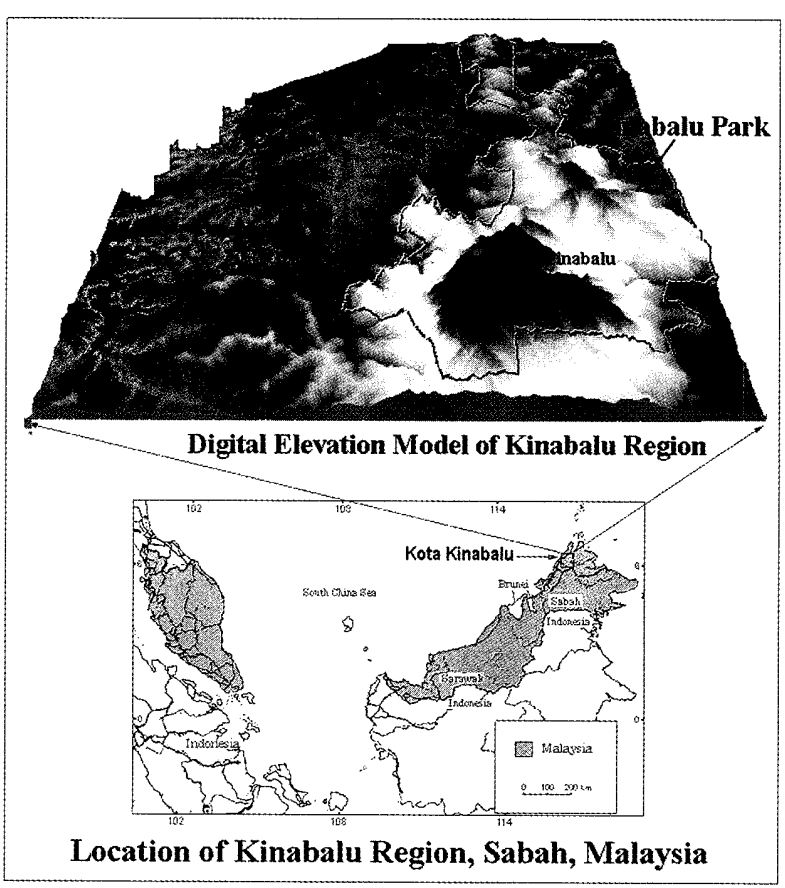

Fig. 1 Location and digital elevation model of the study area

area is diverse in its ecosystems. This area consists of lowlying flood plains at coastal areas to a rocky mountain at 4,095m (Mount Kinabalu). This is the highest peak between the Himalayas and Mount Whelm in Irian Jaya. Mount Kinabalu has been protected by Kinabalu Park since 1964. The mountain is characterized by difficult terrains, vast areas \& most importantly, it comprises fragile ecosystems. Mean air temperature decreases from over $30^{\circ} \mathrm{C}$ at lowland areas to about $10^{\circ} \mathrm{C}$ at $3,700 \mathrm{~m}$.

Forest ecosystems of Kinabalu area are very diversified, from mangroves at the coastal area to lowland rain forest, montane rain forest and sub alpine forest. The altitude gradient is the main factor for the altitudinal zonation of the vegetation. Ultra basic forest, originating from special geological substrates is also found. Based on the dominant type, species composition and structure, KITAYAMA (1991b) has classified the vegetation into lowland, lower and upper montane rain forests, lower and upper sub alpine forests and alpine scrub. In general, the biodiversity of the vegetation decreases with altitude. Though, the pattern is modified by the factor of geological substrate. As altitude increases, the biodiversity of ultra basic forest decreases with a greater rate than that of the non-ultra basic forest (AibA and KITAYAMA, 1999).

\section{MATERIALS AND METHODS}

The satellite images (path: 118, row: 56) acquired were Landsat-MSS data on January $12^{\text {th }}, 1973$ (MSS73) and Landsat- 
TM data on June $14^{\text {th }}, 1991$ (TM91) and on April $8^{\text {th }}, 1996$ (TM96).

Pre-processing and Geometric correction

The MSS data has very light striping effect and histogram matching was carried out to make the apparent distribution of brightness values in the two images as close as possible. Accurate geometric co-registration of a multi-temporal image set, with root mean square error (RMSE) of 0.25-0.5 pixel or 1 pixel at the most, is necessary for accurate change detection (Mouat et al., 1993, Munyati, 2000). In this study, the TM96 image was firstly geocoded to the Universal Transverse Mercator projection and other images were registered to the TM96. The TM96 image was geocoded with an affine transformation model by collecting 22 ground control points (GCPs) on a shade image constructed based on topographic maps $(1: 50,000)$. RMSE of $44.12 \mathrm{~m}$ or less than 1.5 pixels were resulted. Nonetheless, this will not have major influence on the detection analysis because the geometric registration accuracy of the MSS73 and TM91 to TM96 were within 1 pixel. The RMSE of the registration of the TM91 to the TM96 with 39 GCPs was $10.3 \mathrm{~m}$ or 0.34 pixels. The RMSE of the registration of the MSS73 to the TM96 with 30 GCPs was $18.78 \mathrm{~m}$ or 0.63 pixels.

\section{Radiometric Correction}

Atmospheric correction especially the path radiance component should be removed prior to normalization. Varying conditions of the atmosphere caused by meteorological and solar angle variations, influence and change the spectral reflectance of materials on the ground. Amount of electromagnetic energy detected by a sensor influenced by the atmosphere through scattering, absorption and refraction. Degree of influence is wavelength dependent. Of these, scattering account for the biggest part of the influence (SIEGAL et al., 1980). Other effects can be ignored because they account for relatively small proportion of the satellite brightness values. The scattering effect on Landsat data is an additive component and can be corrected by dark object subtraction. The dark object for each band of a scene is obtained from the histogram method. The left part of histogram of each band of the Landsat images is examined interactively on the computer screen for probable haze influence. To avoid obtaining local minimum values, the histograms of the whole scenes are used. The haze influence is indicated by a sharp increase in the number pixels at some non-zero digital number (DN). Started with the minimum DN, if the number of pixels of a DN in a particular band increases sharply, it can be regarded as a haze value (CHAvez, 1988).

Absence of in situ data of the atmospheric conditions in the study area during the satellite overpass has made the correction of other atmospheric effects a difficult task.
Accuracy of atmospheric correction with a standard atmospheric model cannot be verified and any error in the correction process might have propagated undetected into subsequent analysis (ADAMS et al., 1995). For change detection studies that involve multi-temporal satellite data, correcting and calibrating these effects one by one are usually beyond the financial and technical means in most cases (ELVIGE et al, 1995).

Relative radiometric normalization which substantially reduces the inter-scene variability resulting from the changes other than the land cover change, is preferred (e.g. MunYATI, 2000 and Elmore et al., 2000). It uses one image as reference and adjusts the brightness values of other images to match the reference image. In this study, the relative radiometric normalization based on pseudo-invariant features (SCHOTT et al., 1988) is adopted to correct at once all the inter-scene radiance variability due to factors mentioned, including atmospheric factors (e.g. VOGELMAnN, 1988, AwAYA and TANAKA, 1996, MunYati, 2000 and Elmore et al., 2000). It uses one image as reference and adjusts the brightness values of other images to match the reference image. The TM96 is chosen as the reference image for the relative radiometric normalization procedure because it is most recent and has more ground truth sources.

The pseudo-invariant features or constant reflectors over time, common to all images, were carefully selected. The socalled pseudo-invariant features are bare surface and calm water surface do not, in theory, change over time in terms of reflectance. The samples of the pseudo-invariant features have to be selected very carefully to ensure that they are the genuine ones. Theoretically, they should occupy the upper end and lower end of the feature space between every two images for each band so that the image can be normalized to the reference image. For this, water samples, which occupy the lower end space, were taken from bay area where sea surface condition is calm. The bare surface samples were acquired on bare land and rock areas, and they occupy the upper end space. Normalization equations were then derived from regression analyses for adjusting the $\mathrm{DN}$ values of the multitemporal satellite images to the TM96. The regression models contains an additive component that corrects for differences in path radiance between dates which are not fully accounted in the individual scene based subtraction, and a multiplicative term that corrects for the differences in detector calibration, solar angle, earth/sun distance, atmospheric attenuation and phase angle between dates (MUNYATI, 2000). Upon removal of these variations, changes in the $\mathrm{DN}$ values can be related to changes in cover surface conditions. The normalization equations are shown in Fig. 2.

\section{Detection Algorithm}

There are many change detection algorithms available and are usually based on the original band data or transformed 


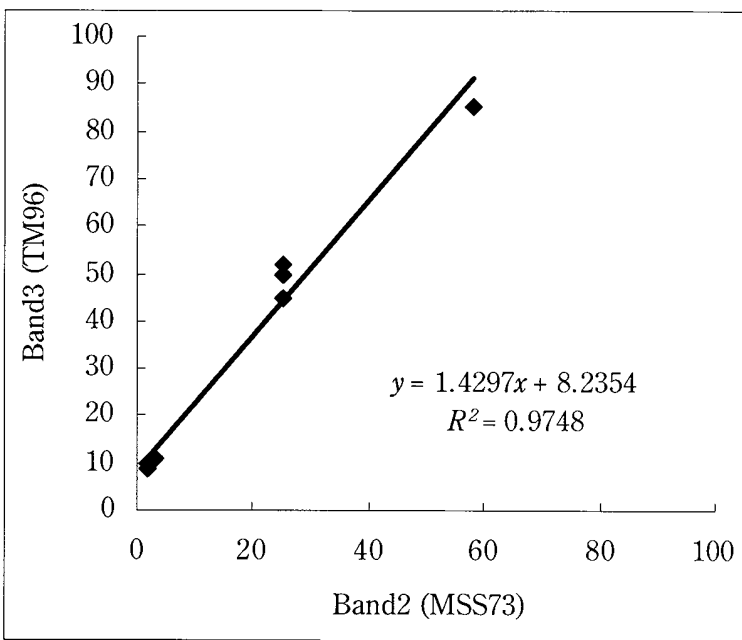

(a)

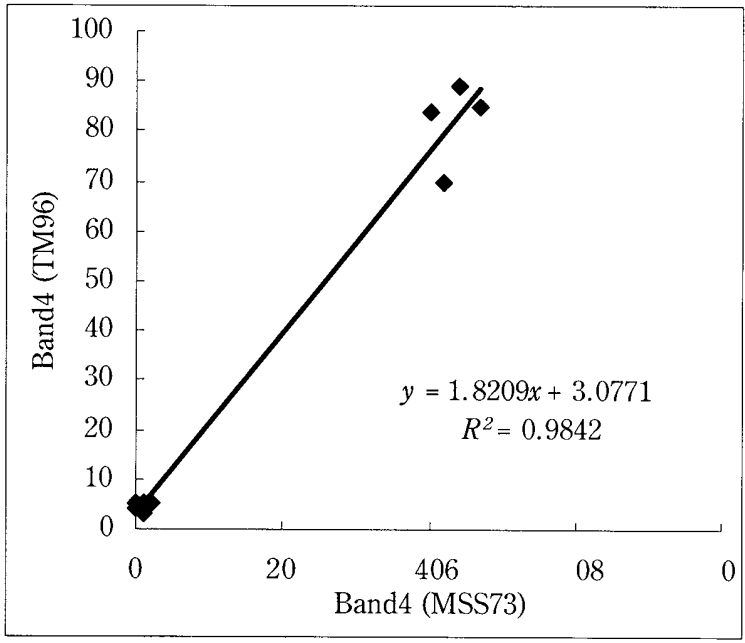

(c)

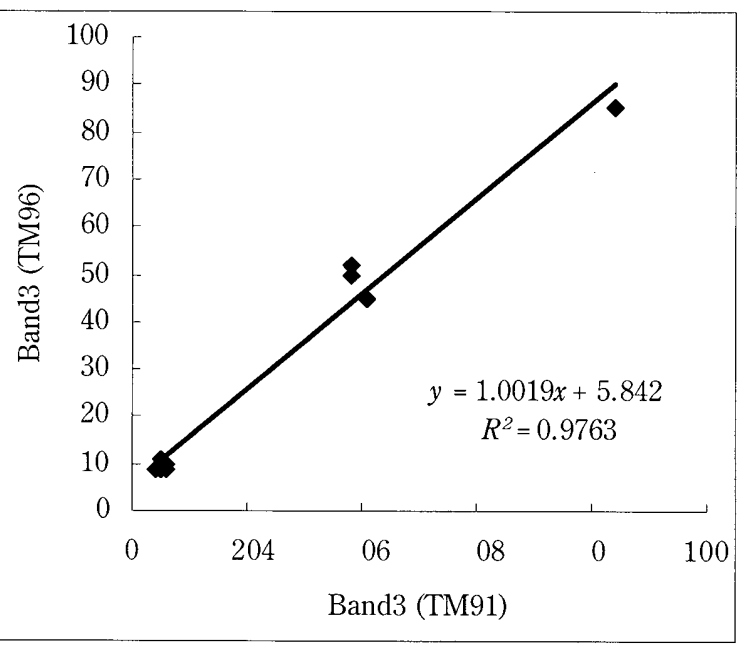

(b)

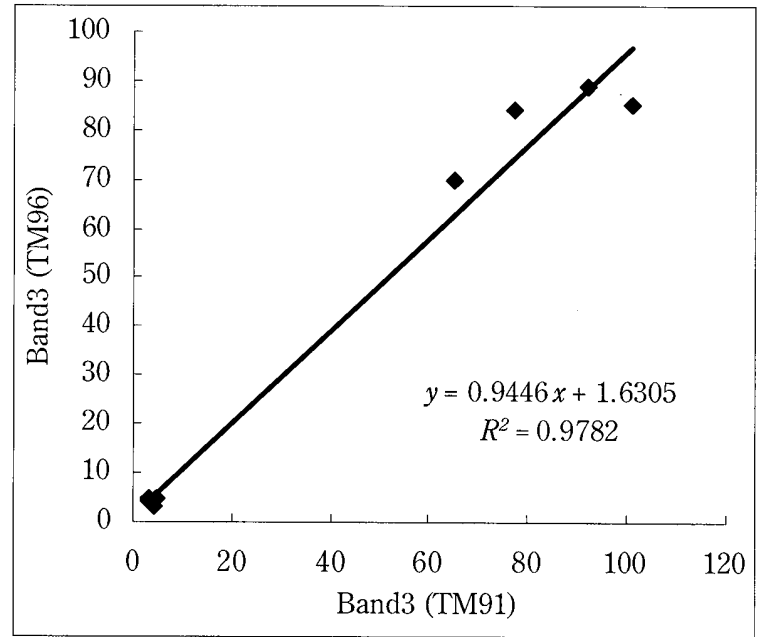

(d)

Fig. 2 Normalization of Landsat-MSS of 1973 (MSS73) and Landsat-TM of 1991 (TM91) to Landsat-TM of 1996 (TM96).

(a) Band2 of MSS73 to Band3 of TM96, (b) Band4 of MSS73 to Band4 of TM96,

(c) Band3 of TM91 to Band3 of TM96 and (d) Band4 of TM91 to Band4 of TM96.

variables. Vegetation index is one of the most widely used transformed variables. It is usually developed by taking the difference between the Near Infrared (NIR) and Red (R) regions. The $\mathrm{R}$ region comprises absorption wavelengths of chlorophyll of green vegetation while the NIR region consists of highly reflected wavelengths due to internal leaf structure of the leaf (TUCKER and MAXWELL, 1976).

This study employs the most widely-used NDVI in an image differencing algorithm. The NDVI is defined as below:

$$
N D V I=\frac{N I R-R}{N I R+R}
$$

The NDVI is a commonly used indicator of vegetation parameters in remotely sensed data because there is a reasonable correlation with vegetation abundance and other important ecological parameters, such as leaf area index (ELMORE et al., 2000). The NDVI computed using the equation is added with value of one and multiplied with a hundred so that the non-vegetation pixels will have a value of 100 . Figs. 3a, 


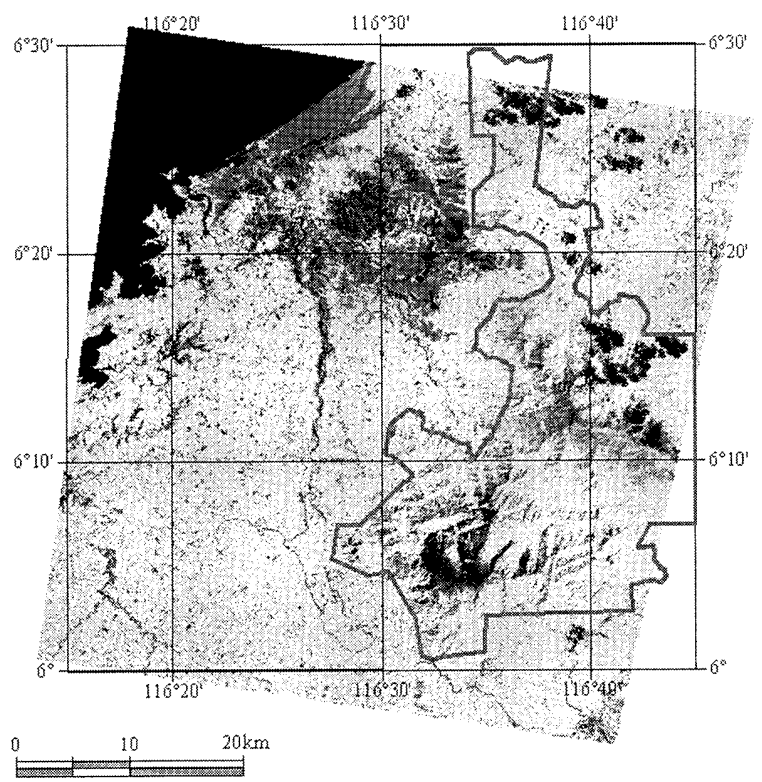

Fig. 3a The NDVI Image of MSS73

Note: Brighter colors mean higher vegetation biomass, in general.

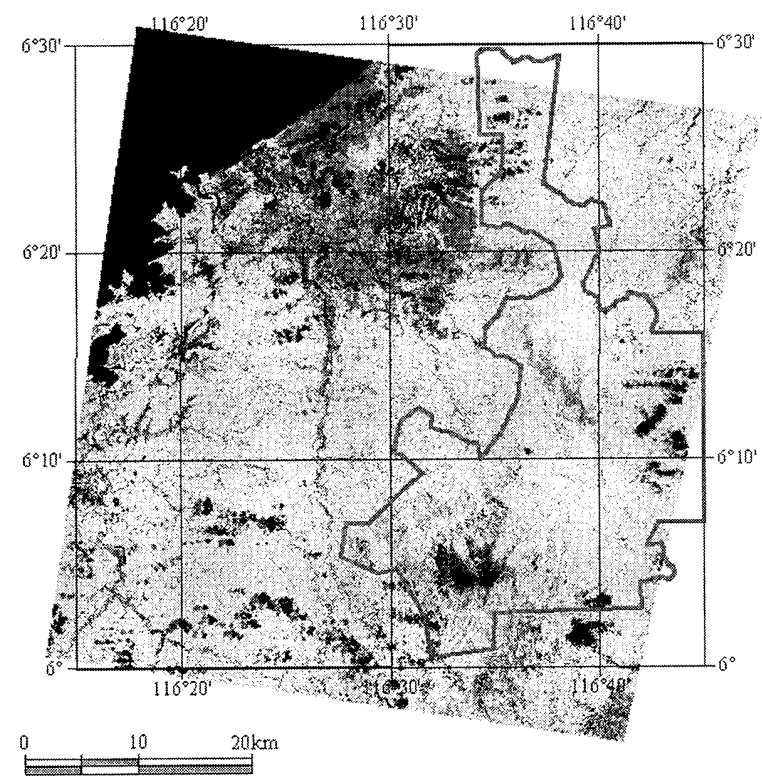

Fig. 3c The NDVI Image of TM96

Note: Brighter colors mean higher vegetation biomass, in general.

3b and 3c show the NDVI images of MSS73, TM91 and TM96, respectively. Brighter colors in the images indicate higher biomass or vigor of the vegetation cover and vice-versa.

To detect the deforestation, we used the NDVI with image

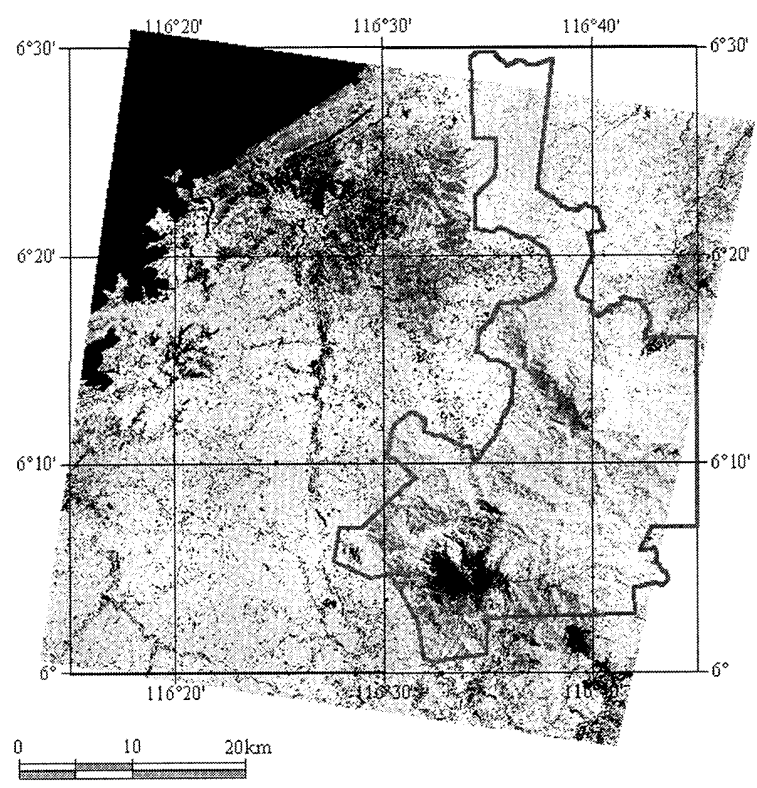

Fig. $3 \mathrm{~b}$ The NDVI Image of TM91

Note: Brighter colors mean higher vegetation biomass, in general.

differencing technique. This technique requires that each pixel's value in the image be subtracted from its corresponding pixel's value in another image. The image resulted represents the changes between the two time periods. Pixels exhibiting a significant value change can be expected to lie in the tails of the distributions of the difference image, whereas the remaining pixels should be grouped about the mean. Image differencing may be applied to a single band (in which case it is called univariate image differencing) or to multiple bands.

The image differencing with NDVI or NDVI image differencing algorithm has been used in change detection studies such as forest canopy change (NELSON, 1983), landslide detection (DHAKAL, 1999), and vegetation change in semi-arid area (ELMORE et al., 2000). It is a simple and straightforward approach where changes in a pixel at line $i$ and column $j$ of band $k\left(\triangle N D V \eta_{i j}\right)$ is computed as below:

$$
\Delta N D V I_{i j}=N D V I_{i j}(t 2)-N D V I_{i j}(t 1)+C
$$

\section{where}

$t 2$ and $t 1$ : date 2 and date 1 , respectively $C$ : constant (taken as 127)

The date 2 image is subtracted from that of the date 1 image to generate a change image. A constant of 127 to make the no change pixels in the midpoint of the 8-bit data space. To its left, it represents decreases in biomass or vegetation amount for the NDVI. To its right, increase in biomass or 
vegetation amount for the NDVI is expected. We are interested only in deforestation and thus the left tail of the change image is of interest.

\section{Accuracy Assessment}

There is no theoretical basis on how a threshold of change or no change can be established. Standard deviation from the mean is often employed and has been usually found suitable (JENSEN, 1996). RidD and LiU (1998) derive the optimal threshold by testing the thresholds from 0.1 to 3 standard deviations. This is especially useful for investigating area, which is not familiar to researchers. On the other hand, MichaleK et al. (1993) derived the threshold by examining the pixel values of deep water. It was however too relaxed and generated a large number of insignificant change pixels.

In general, the approach that determines the optimal threshold is not other than the one that gives the best result. That means ground truth is the most critical factor. While it is possible to collect ground reference information for the most recent remotely sensed data, it is impossible to go back in time and collect the historical ground reference information (JENSEN et al., 1995). Thus, ground truths for historical images are totally dependent on any data available especially aerial photographs, maps and photographs. It is not difficult to sample areas of no change but it is difficult to sample on areas of change. An intuitive straightforward interpretation of the word of "change areas" necessitates samples of same location to know if changes have taken place over the period. Moreover, changed area is usually a very small percentage of

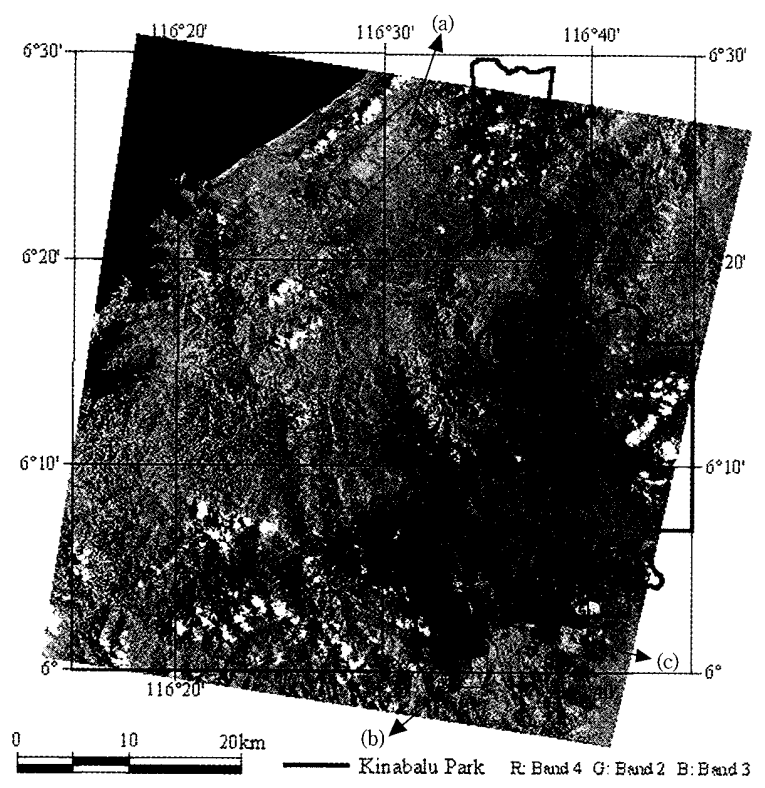

Fig. 4 Location of test sites.

(a) Kota Belud area; (b) Kundasang area;

(c) Mamut area. The background image is TM96. the total area so that the available ground truth source may not include any of the changed area. If ground truth is available, threshold level can be modified until it gives highest accuracy (DHAKAL, 1999).

Accuracy assessment strategy employed was to first verify the effectiveness of the NDVI image differencing with the multi-sensor data at test sites. The accuracy of change detection was assessed using a pair of images (TM96 and MSS73). Three test sites covered by reliable groundtruths in both periods were identified. One of the sites is located at the northwestern part of the study area in Kota Belud area. The remaining sites are in Kundasang area and Mamut area, in the southern part of the study area (Fig. 4).

The accuracy was assessed using the error matrix of change and no-change. Both overall accuracy and Kappa coefficient were used to determine the most accurate threshold. The overall accuracy measures accuracy of the detected changes as a whole i.e. the ratio of the total number of correctly classified samples to the total number of samples. However, the overall accuracy has a tendency to be biased toward the category with a larger number of samples (NELSON, 1983; SINGH, 1986), which are the samples of no change areas. In contrast, the Kappa coefficient takes into account the degree of agreement expected by chance by using all the elements of the error matrix and not just main diagonal to its calculation. The accuracy it gives is the proportion of agreement obtained after removing the proportion of chance agreement as it uses all the elements in the error matrix to derive an accuracy measure. It is widely used in accuracy assessment in remote sensing studies (CONGALTON, 1991).

\section{RESULTS AND DISCUSSION}

Accuracy of Deforestation Detection

Based on the ground truth points at the three test sites, the optimal threshold was evaluated iteratively using the two accuracy measures. Fig. 5 shows how the accuracy measures change with the thresholds. The optimal threshold was determined when the Kappa coefficient and overall accuracy were highest i.e. $63 \%$ and $93 \%$, respectively. However, false deforestation on paddy areas were also detected. The accuracy was improved after the false change pixels were removed. The

Table 1 Accuracy of NDVI image differencing for the deforestation detection before and after removal of false deforestation pixels

\begin{tabular}{llll}
\hline Accuracy measure & NDVI $^{\mathrm{a}}$ & & NDVI (corrected) $^{\mathrm{b}}$ \\
\hline Khat accuracy & 62.99 & & 67.89 \\
Overall accuracy & 93.05 & 94.26 \\
\hline
\end{tabular}

a: NDVI image differencing. b: Accuracy after false change pixels on paddy areas were corrected. 


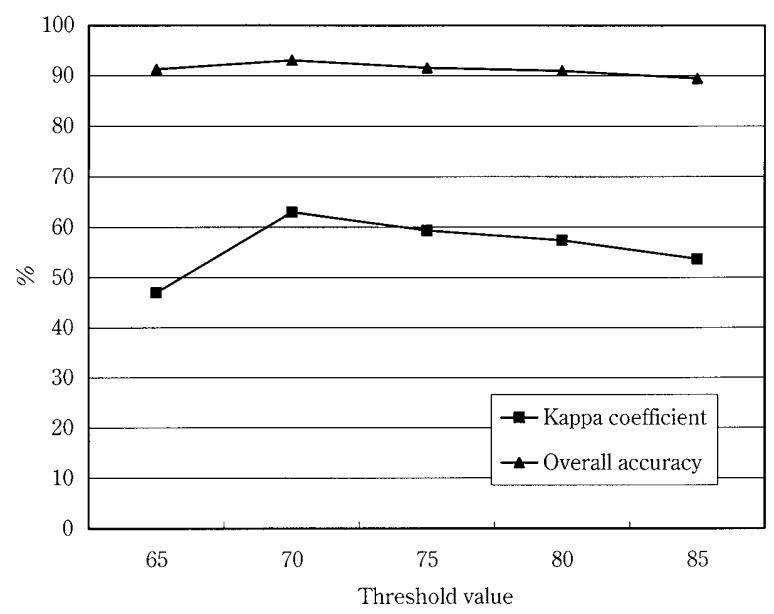

Fig. 5 Accuracy of various threshold values. Threshold of 70 gives the best deforestation detection accuracy.

improvement for the Kappa coefficient was $5 \%$ whereas the total accuracy only improved marginally (Table 1).

Deforestation for the Two Detection Periods

The results of deforestation detection are shown in Figs. 6 and 7 for period I and period II, respectively. In general, the threshold detects distinctive changes of vegetation cover i.e. from vegetation to non-vegetation. This means crop harvest may also be detected as 'deforestation'. In this study, some of the deforestation detected in period I were actually paddy areas. The paddy areas are found in the Kota Belud area where the establishment was started before the Landsat program in 1972. The forests at the coastal plains in the northeastern areas were wiped away by mainly paddy cultivation, and cattle ranching in post-war periods. The paddy areas can be interpreted on aerial photographs of 1972 and confirmed through field interview. The confusion was because of different growing condition in the two images. The paddy was growing actively in MSS73 but was not in the active growing condition in TM96. The paddy areas were intepreted as active growing green vegetation when MSS73 was taken because the NDVI value was relatively high. In TM96, its relatively low NDVI value indicated that the paddy was not growing actively. The false deforestation areas were easily removed with the availability of a land use map of 1984 .

The algorithm has estimated 2,090ha of forest cleared during the first period or $0.8 \%$ of the total land area. In second period, deforestation is small, at 355 ha or $0.13 \%$ (Table 2). Arbitrarily, the first period has a deforestation rate of $116 \mathrm{ha} /$ year, which is more than 1.5 times than that of the second period. In total, 2,445ha of forest were deforested in Kinabalu area from 1973 to 1996

While the remote sensing technology gives the

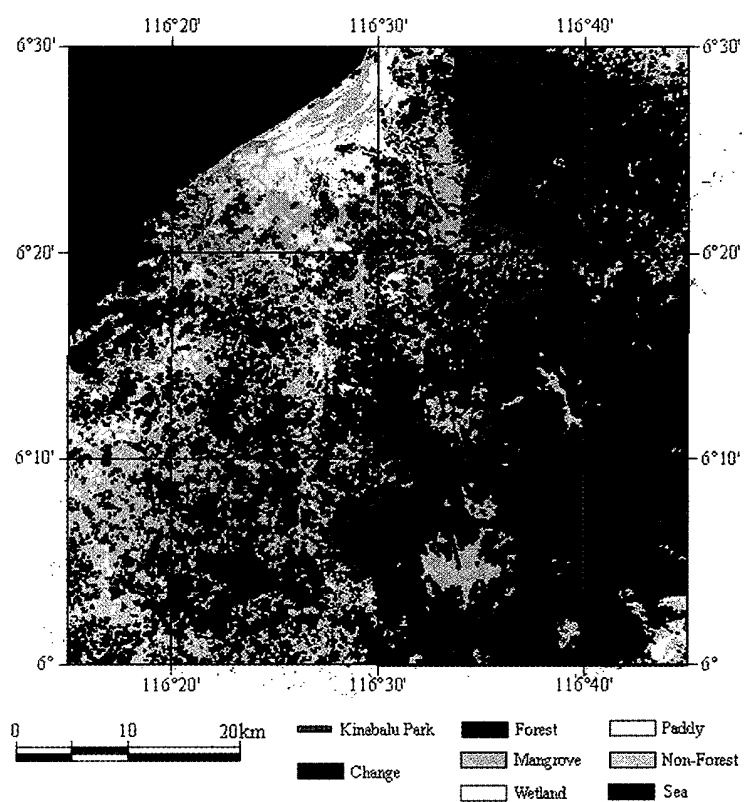

Fig. 6 Deforestation between 1973 and 1991 detected by the NDVI image differencing algorithm. The background image is the land use map of 1984. Red color areas on the pink color areas are false deforestation areas.

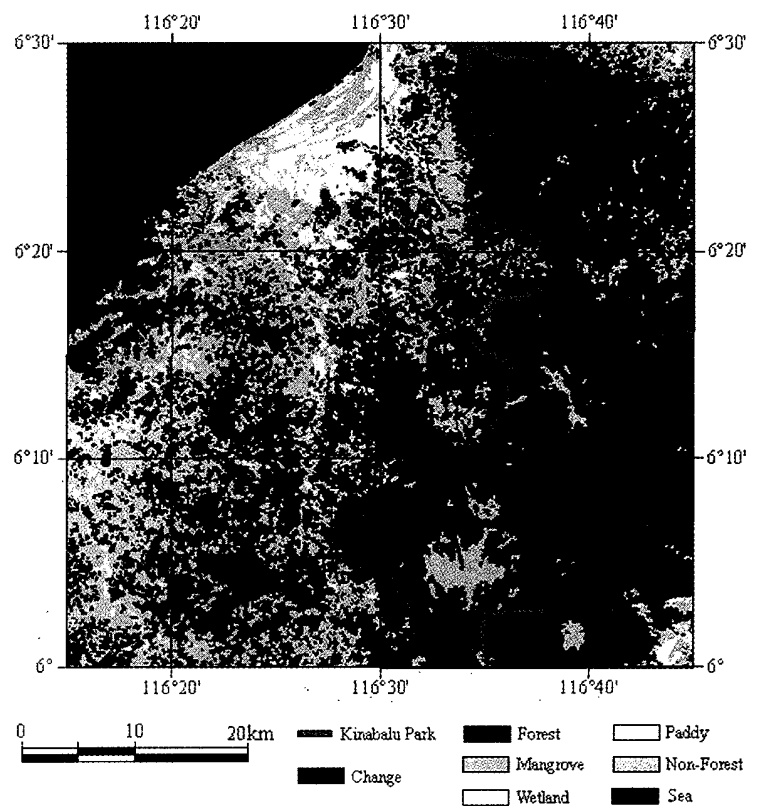

Fig. 7 Deforestation between 1991 and 1996 detected by the NDVI image differencing algorithm. The background image is the land use map of 1984

deforestation estimate, the types, distribution and causes have to be interpreted. In period I, relatively large-scale deforestation concentrates at areas near the southern part of the park. Forest clearing at the mining site has contributed to

\section{J. For. Plann. 10:31-40(2004)}


Table 2 Estimates of Deforestation in the Two Change Periods

\begin{tabular}{lcccc}
\hline Change Period & Change (ha) & No Change (ha) & Total Area (ha) & Percent of Change (\%) \\
\hline I : $1973-1991$ & $2,089.98$ & $263,345.94$ & $265,435.92$ & 0.79 \\
II : $1991-1996$ & 355.14 & $265,080.78$ & $265,435.92$ & 0.13 \\
\hline
\end{tabular}

a major portion of the deforestation in period I. In fact, the copper mine was established at a $25 \mathrm{~km}^{2}$ forest, which legally excised from Kinabalu Park in 1974. The park was compensated with Mount Templer area $\left(93 \mathrm{~km}^{2}\right)$ in the northern part and the state government was granted administrative authority in 1984. Under the new Parks Enactment 1984, boundary of the park was redefined but this has resulted in the loss of Pinosuk Plateau, the main site of the Royal Society Expeditions in 1961 and 1964, and Bukit Hampuan, a valuable site for studying ultra basic vegetation (LIEW, 1996). Pinosuk Plateau is alluvial flatland that is relatively fertile for cultivation. The de-gazetted lands were developed for a large scale diary farm, and temperate vegetable cultivation. Some areas were converted to housing lots. Commercial agriculture has significantly cleared some forests in the southern part. It can easily be observed in the field that the forest clearings are getting very close to the park boundary.

In the period II, deforestation at the mining site continued at a much smaller rate. Small scale slash-and-burn agriculture has been clearing the forest in both periods. Differs from the large scale development, the slash-and-burn agriculture scatters over the whole area. Despite elevation more than $1,200 \mathrm{~m}$ and slopes steeper than $30^{\circ}$, shifting cultivation has been practiced by the local community. The impacts of the shifting cultivation on the environment, including soil, water and biodiversity, were documented in JOSHI and KAR (1993). The impacts of land use activities can also be identified by using an environmental impact matrix where the environmental impacts of development activities are evaluated on various resources (SENES and TocCoLINI, 1998).

The relatively low annual deforestation rate over the study period gives an impression that no significant deforestation has occurred. In fact, the results have shown that the Kinabalu Park has played an invaluable role in protecting the last big piece of primary forest in the area. It is expected to continue with such role in future. The change detection study has two implications on conservation sector. The first is that conservation target in this region is the secondary forest that is recovering from previous disturbance. Certain degree of degradation on the secondary forest is expected. To identify forests important to be conserved, appropriate conservation planning approach is essential. Second, the results also suggest the needs to strengthen forest conservation management of Kinabalu Park. This is because of the fact that Kinabalu Park contains the big piece of primary forest which is rich in timber resource and thus subject to illegal logging activity. The relatively low deforestation rate also means higher pressures on the remaining high forests. Agricultural activities in the surrounding areas are expected to pose more pressures on the protected forests. Commercial agricultural activities (temperate vegetable) are restricted by the Southern boundary of the Kinabalu Park. In other surrounding areas, shifting cultivation activities should be monitored from time to time. The boundary areas adjacent to villages are more exposed to encroachment.

\section{The Multi-sensor Remote Sensing Approach}

Nevertheless, it is noted that the estimate of the total deforestation may be an underestimate. The temporal interval for period I (1973-1991) was considerably long and provide sufficient time for deforested areas to regenerate. The vigorous regenerated vegetation in 1991 may exhibit very similar NDVI value compared with that of the corresponding forest area in 1973. Actually, many of the available images of Landsat-TM and Landsat-MSS were covered by clouds. Cloud coverage has been a limiting factor to the use of satellite remote sensing in the tropics. In that regards, multi-sensor remote sensing approach offers more satellite data for deforestation detection as well as for other change detection in the tropics.

Although multi-sensor remote sensing approach may have fewer options of techniques, it is advantageous in terms of temporal resolution. The use of Lansat-MSS, in addition to the Landsat-TM, for instance, enables changes occurred back to 1972 when the Landsat-1 mission launched, to be investigated. The main obstacle is that different wavelength range of sensors. MUNYATI (2000) used post-classification comparison technique on the three common bands of the Landsat-MSS and TM for detecting wetland change. However, it is often reported that the post-classification comparison technique has relatively low accuracy because the accuracy of this technique is the product of the accuracy of classification in two dates (YUAN et al., 1999). It can be argued whether the NDVI of Landsat-TM and Landsat-MSS are comparable because the wavelengths of the NIR and R bands of the two sensors are slightly different. However, with the reliable ground truths, this study shows satisfactory results for the deforestation detection. In some studies, various sophisticated techniques were applied without sufficient ground truth of the changes detected especially in the tropics where ground truth data are very limited (SINGH, 1989). After the relative normalization, the values of the NIR and R bands of Landsat-MSS should 
approximate the Landsat-TM. However, this issue should be investigated further. Image fusion techniques (e.g. CARPER et al., 1990; PELLEMANS et al., 1993) should be explored to enable integration of more types of sensor data for change detection.

\section{CONCLUSIONS}

This paper presents a case study of deforestation detection at Kinabalu area, Sabah, Malaysia by using multisensor remote sensing approach. While there are issues to be investigated further, we were able to show how the approach can provide information about deforestation in terms of area and distribution so that causes can be interpreted. These information are important for planning purposes. Given the size of the park with a perimeter of $205 \mathrm{~km}$ (PHUA and MiNOwA, 2000) and very inaccessible in certain parts, the multi-sensor remote sensing approach is potentially very useful especially to the management of Kinabalu Park. This approach is relatively simple and straightforward to be used by the authority. The approach provide more opportunities to obtain 'cloud-free' satellite images so that it is possible to identify areas that subject to high deforestation risks in terms of deforestation area and frequency that are neighboring the park. This could aid the improvement in resource optimization for protection.

\section{LITERATURE CITED}

Adams, J. B., Sabol, D. E., Kapos, V., Filho, R. A., Roberts, D. A., SMITH, M. O. and GILlesPIE, A. R., (1995): Classification of multispectral images based on fractions of endmembers: Application to land-cover change in the Brazilian Amazon. Remote Sens. Environ. 52: 137-154

Aiba, S. and KiTAYAMA, K., (1999): Structure, composition and species diversity in an altitude-substrate matrix of rain forest tree communities on Mount Kinabalu, Borneo. Plant Ecol. 140: 139-157

AndréfouËt, S., Muller-Karger, F. E., HochBerg, E. J., Hu, C. and CARDER, K. L., (2001): Change detection in shallow coral reef environments using Landsat 7 ETM+ data. Remote Sens. Environ. 78: $150-162$

AwAYA, Y. and TANAKA, N., (1996): Successional and seasonal pattern of spruce spectra as a basis of boreal forest monitoring. Proceedings of the $26^{\text {th }}$ International Symposium on Remote Sensing of Environment, ISRSE and CRSS, Vancouver.

CARPER, W. J., LILLESAND, T. M. and KIEFER, R. W., (1990): The use of intensity-hue-saturation transformations for merging SPOT panchromatic and multispectral image data. Photogramm. Eng. Remote Sens. 56(4): 457-467

Chavez, P. S., (1988): An improved dark object subtraction technique for atmospheric scattering correction of multispectral data. Remote Sens. Environ. 24: 459-479

CoHen, W. B. and Fiorella, M., (1999): Comparison of methods for detecting conifer forest change with Thematic Mapper imagery. (In Lunetta, R. S. and Elvidge, C. D. (eds.): Remote Sensing Change Detection: Environmental Monitoring Methods and
Applications). Taylor \& Francis Press, London, 318pp

COLLINGE, S.K., (1996): Ecological consequences of habitat fragmentation: Implications for landscape architecture and planning. Landsc. Urban Planning 36: 59-77

Congalton, R. G., (1991): A review of assessing the accuracy of classifications of remotely sensed data. Remote Sens. Environ. 37: 35-46

DhaKal, A. S., (1999): Remote Sensing and Geographic Information Systems Techniques for Landslide Hazard Evaluation and Prediction Models. Unpublished Ph.D Thesis of University of Tsukuba, Japan, 143pp

DrECHSLER, M. and WisSEL, Ch., (1998): Trade-off between local and regional scale management of metapopulation. Biol. Conserv. 83(1), 31-41

Elmore, A. J., Mustard, J. F., Manning, S. J. and Lobell, D. B., (2000): Quantifying vegetation change in semiarid environments: Precision and accuracy of spectral mixture analysis and the Normalized Difference Vegetation Index. Remote Sens. Environ. 73: $87-102$

Jensen, J. R., (1996): Introductory Digital Image Processing. Prentice-Hall, Englewood Cliffs, New Jersey, 316pp

Jensen, J. R., Rutchey, K., Kouch, M. S. and Narumalani, S., (1995): Inland wetland change detection in the Everglades water conservation area $2 \mathrm{~A}$ using a time series of normalized remotely sensed data. Photogramm. Eng. Remote Sens. 61(2): 199-209

Joshi, H. and KAR, K., (1993): Environmental impacts of shifting cultivation and its management: A case study of Mizoram, India. J. Environ. Sys. 22 (3): 249-267

KITAYAMA, K. (1991a): Human impacts and implications for management in Mount Kinabalu Park, Sabah, Malaysia. A Collection of Papers Arising from an International Consultation on Protected Areas in Mountain Environments, 26 October-2 November 1991, Honolulu, Hawaii.

KrTAYAMA, K. (1991b): Vegetation of Mount Kinabalu Park, Sabah, Malaysia. East-West Center, Honolulu, Hawaii, $45 \mathrm{pp}$

Lamberson, R. H., Noon, B. R., Voss, C. and McKelvey, R., (1994): Reserve design for territorial species: the effects of patch size and spacing on the viability of the Northern Spotted Owl. Conserv. Biol. 8: 186-195

LIEW, S.P., (1996): Kinabalu Park: Past, present and future. (In Wong, K. M. and Phillipps, A. (eds.): Kinabalu: Summit of Borneo). The Sabah Society and Sabah Parks, Kota Kinabalu, Sabah, 544 pp

Mouat, D. A., Mahin, G. G. and Lancaster, J., (1993): Remote sensing techniques in the analysis of change detection. Geocarto Int. 2: $39-50$

Michalek, J., Wagner, T., Luczkovich, J. and Stoffle, R., (1993): Multispectral change Vector analysis for monitoring coastal marine environments. Photogramm. Eng. Remote Sens. 59(3): 381-384

MunyaTi, C., (2000): Wetland change detection on the Kafue Flats, Zambia, by classification of a multi-temporal remote sensing image dataset. Int. J. Remote Sens. 21 (9): 1787-1806

NeLSon, R. F., (1983): Detecting forest canopy change due to insect activity using Landsat-MSS. Photogramm. Eng. Remote Sens. 49: 1303-1314

Pellemans, A. H., Jordans, R. W. and Allewij, R., (1993): Merging multispectral and panchromatic SPOT images with respect to the 
radiometric properties of the sensor. Photogramm. Eng. Remote Sens. 59(1): $81-87$

PhuA, M.-H. and Mrnowa, M., (2000): Evaluation of environmental functions of tropical forest in Kinabalu Park, Sabah, Malaysia using GIS and remote sensing techniques: Implications to forest conservation planning. J. For. Res. 5: 123-131

Powell, G. V. N. and BJoRK, R., (1995): Implications of intratropical migration on reserve design: a case study using Pharomachrus mocinno. Conserv. Biol. 9: 354-362

RiDD, M. K. and LIU, J., (1998): A comparison of four algorithms for change detection in an urban environment. Remote Sens. Environ. 63: $95-100$

Schott, J., Salvaggio, C., and VolchoK, W., (1988): Radiometric scene normalization using pseudoinvariant features. Remote Sens. Environ. 26: 1-16

Senes, G. and Toccolini, A., (1998) Sustainable land use planning in protected rural areas in Italy. Landsc. Urban Planning 41: 107-117

Siegal, B. S., Grllespie, A. R., and Skaley, J. E., (1980): Remote Sensing in Geology. Wiley, New York, 702pp
SingH, A., (1989): Digital change detection techniques using remotely sensed data. Int. J. Remote Sens. 10(6): 989 -1003

SтотZ, D. F., (1998): Endemism and species turnover with elevation in montane avifaunas in the neotropics: implications for conservation. (In Mace, G. M., Balmford, A. and Ginsberg, J. R. (Eds.): Conservation in a Changing World). Cambridge University Press, Cambridge, 308pp

Tucker, C. J. and Maxwell, E. L., (1976): Sensor design for monitoring vegetation canopies. Photogramm. Eng. Remote Sens. 42(11): $1399-1410$

Vogelmann, J. E., (1988): Detection of forest change in the Green Mountains of Vermont using Multispectral Scanner data. Int. J. Remote Sens. 9(7): 1187-1200

Yuan, D., Elvidge, C. D. and LunetTa, R. S., (1999): Survey of multispectral methods of land cover change analysis. (In Lunetta, R. S. and Elvidge, C. D. (eds.) Remote Sensing Change Detection: Environmental Monitoring Methods and Applications). Taylor \& Francis Press, London, 318pp

(Received 8 December 2003)

(Accepted 14 February 2004) 